\title{
Physiological Effects of Pulsed LED Light Added to a Task Lamp to Improve Alertness on Employees of Hospital or Shift Workers
}

\section{Efectos Fisiológicos de Pulsos de Luz de Diodo Adicionados a una Lámpara de Trabajo para Mejorar el Estado de Alerta en Personal de Hospitales o Trabajadores por Turnos}

\author{
C. A. Chaveznava-Treviño', 2, S. Lee², T. Katsuura², Y. Shimomura² \\ 'Universidad de Monterrey \\ ${ }^{2}$ Chiba University
}

\begin{abstract}
The aim of this study is to investigate the effect of a continuous stream of pulses of monochromatic blue pulsed (BP) and a combination of blue and green pulsed (BGP) light-emitting diode (LED) light conditions on physiological responses. This study is an approach to clarify the most suitable LED combination and flickering frequency to evoke alertness when a continuous stream of pulsed LED light is delivered and may suggest applications of continuous pulsed light as support for task illumination for shift workers, hospital nurses, school students or office employees. Combinations were delivered by exposures of BPLED and BGPLED pulses at 100, 200, and 400 Hertz over two background light colors (BLC). Participants were exposed to 12 different light conditions in a counterbalanced procedure. By integrating measures of electroencephalogram (EEG) and pupil constriction; results suggested significant changes in responses during the interaction of BLC, LED, and EEG. Beta waves exhibited a statistically significance $(p<0.05)$ in arousal levels when exposed to BG light, although no active task was involved during exposure. Furthermore, pupil reacted with larger constriction towards BGPLED exposure than towards monochromatic BPLED exposure, thus demonstrating that a continuous stream of pulses can deliver the same irradiance as if delivered in a continuous flow and without affecting perception as no flickering was perceived in any of the conditions by a qualitative evaluation.
\end{abstract}

KEYwORDS: Pulsed LED light; flickering; alertness; physiological effects; pupil behaviour 


\section{RESUMEN}

Este estudio tiene por objetivo determinar cuál es la combinación de luz LED más adecuada y la frecuencia de parpadeo que esta deba tener, para evocar un estado de alerta cuando se emite un flujo continuo de la misma al combinarla con una iluminación de ambiente; y poder sugerir aplicaciones como soporte para la iluminación de tareas para trabajadores por turnos, enfermeras, médicos, estudiantes; o en oficinas y hospitales. Es de original importancia resaltar que en el mercado no existe un producto comercial que se pueda ajustar para apoyar en el trabajo al estado de alerta, se tiene la limitante que estas son pruebas a nivel laboratorio y que posteriores pruebas serán necesarias para validar el producto final. El método usado se basó en las combinaciones que se administraron mediante exposiciones de luz azul pulsada (BPLED) y luz azul y verde combinadas (BGPLED) a frecuencias de 100, 200 y $400 \mathrm{~Hz}$ adicionadas a la iluminación ambiental (BLC). Los participantes fueron expuestos a 12 condiciones de luz diferentes en un experimento balanceado y contrapesado. Mediante la integración de medidas electroencefalográficas (EEG) y de constricción pupilar; los resultados sugirieron cambios significativos en las respuestas durante la interacción de BLC, LED y EEG. Las ondas beta mostraron una significancia estadística ( $p<0.05)$ en los niveles de activación cuando se expusieron a la luz BGPLED, además, la pupila reaccionó con una mayor constricción hacia la exposición a BGPLED que hacia la exposición BPLED monocromática, adicionalmente se demostró que un flujo continuo de pulsos puede proporcionar una irradiación igual a la que se emite en flujo continuo; se concluyó e identificó además la frecuencia $(100 \mathrm{~Hz})$ que mejor evoca estado de alerta encefalográfíca y sin afectar la percepción de los usuarios en cuanto a su percepción del ambiente de acuerdo a la evaluación cualitativa.

PALABRAS CLAVE: Luz LED pulsada; comportamiento pupilar; efectos fisiológicos; estado de alerta cerebral;

flujo continuo de pulsos

\section{Correspondencia}

DESTINATARIO: Carlos Alberto Chaveznava Treviño

INSTITUCIÓN: Universidad de Monterrey

DIRECCIÓN: Av. Morones Prieto \#4500 Poniente,

Col. Jesús M. Garza, C. P. 66238, San Pedro Garza

García, Nuevo León, México

CORREOELECTRÓNICO: carlos.chaveznava@udem.edu

\section{Fecha de recepción:}

25 de febrero de 2019

Fecha de aceptación:

26 de noviembre de 2019 


\section{INTRODUCTION}

Exposure to pulsed light results in non-visual physiological responses in humans ${ }^{[1]}[2][3][$ [4] [5] [6] [7] [8] [9]. The present study aims to investigate whether such non-visual effects are influenced to a greater extent by the frequency of flickering or by the combination of colours of lighting, this research obeys to a previous experiment in which an intervention of Blue Pulsed LED was used as an addition to a task lamp in order to improve the state of alertness in humans when a continuous stream of pulses at $100 \mathrm{~Hz}$ was delivered to a conventional workspace ${ }^{[10]}$. The actual study was developed in order to find the electroencephalogram (EEG) behaviour to determine differences among flickering frequencies in order to determine which one evokes the most and apply it to a prototype desk lamp.

It is known that light influences physiologically to all species, humans among them of course. When situation is in an outdoor scenario the main source is sunlight, but nowadays in the modern world, artificial lighting is of great influence to humans on work efficiency and health ${ }^{[11]}$. There are visual effects caused by light, denoted as visual effects and non-visual or non-image-forming (NIF) effects that are also elicited.

Regarding the type of light, evidence shows that exposure to blue light delivers the strongest non-visual effect ${ }^{[12]}$; some other research indicated that blue light has an increased pupillary constriction effect ${ }^{[13]}$,

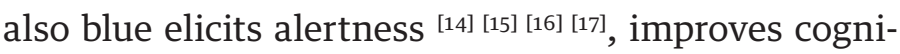
tive performance ${ }^{[18]}$, suppresses melatonin ${ }^{[19]}$ and changes the phase of circadian rhythms ${ }^{[20]}$.

Furthermore, there are reports that have revealed the greater non-visual responses evoked by intermittent pulses rather than a continuous beam of light [21] [22] [23]. In a parallel study from a joint research, the mixing of short pulses $(100 \mu \mathrm{s})$ of blue light with a white light background, was observed an increase in pupillary constriction due to the blue light intervention although blue color was not perceived by the participants in a way that they could continue their work without feeling that the workplace surface or area was changed to a bluish tonality ${ }^{[10]}[24]$. This type of result show that blue can be added to general illumination as long as it is not perceived by human eye, the effect can be delivered without affecting perception and may allow worker to maintain a high arousal level as the one needed in Hospitals, Schools or an Office setting.

It is of a high importance to make studies like this as in certain jobs the state of alertness has to be high due to the relevancy of the decisions taken; a typical example is in the so called blue rooms in Hospitals where careful attention has to be taken into the interpretation of results. Other cases like nursing stations also in Hospitals or quality control sections in the manufacturing industry also require; needless to say to evoke alertness in students or office workers can be of a good benefit for the outcomes on their respective duties.

When talking about light, sometimes there is a misunderstanding about the use of it in regards to quantity or intensity of light. Let us remember that irradiance of light refers to the radiant flux, either power or quantity, received by a surface per unit area (in our case $\mu \mathrm{W} / \mathrm{cm}^{2}$ ). Therefore "intensity" is the term so assigned to it $\left(\mu \mathrm{W} / \mathrm{cm}^{2} / \mathrm{sec}\right)$. And, as mentioned before, if short pulses of blue light elicits alertness [14] [15] [16] [17], then, the aim of this study has a compelling compromise in to research on the non-visual effects of irradiance by a flickering light in order to verify the most suitable and less perceivable frequency for the end user.

In recent years there has been some developments in regards to provide sources of light in benefit of health; desk lamps that provide blue light for depression or seasonal affective disorder treatments, as well as circadian light programmed in the cell phones or com- 
puters to avoid eye strain; but commercially available devices that can provide alertness for shift workers or precision task functions are seldom seen, so this is actually the area we are attempting to revise and provide some knowledge to it.

Back in 2002 a novel photoreceptor was found in the mammalian retina ${ }^{[25]}$, this photoreceptor, called intrinsically photosensitive retinal ganglion cells (ipRGC), was confirmed to respond to blue light (short wavelength) of around $480 \mathrm{~nm}$. Then, ipRGC activity has a parallel photo response to the pupillary behaviour related to the course of amplitude and time when constriction of pupil is elicited. Green light has also been researched as an alerting effect source when applied to an ambiance light and, as in other studies the ipRGCs' activity have been reported to be related to the effect of light on alertness and cognitive performance [26] [27] [28] [29] [30], we measured pupillary constriction as a way to corroborate the ipRGCs activity with the alpha and beta waves presence. Assuming that if we have a remarked constriction in pupil that may confirm that the presence of alpha or beta waves is related to the presence of blue light and not to a different influential factor.

In previous study we found that the pupillary constriction under a $100 \mu$ s pulsed blue light condition was significantly greater than that under a steady blue light condition; the two conditions had equal blue light components [31] [32]. Here we conducted an experiment based on different flickering's of light taking into account previous studies that were working with short pulses of light this in order to investigate the effect of a continuous stream of pulses on physiological responses. Selection of frequencies had to be above $100 \mathrm{~Hz}$ to avoid any danger in the participants, duty ratio was defined following previous researches in order to define the frequency that could elicit the most alertness and not being perceivable by the naked eye ${ }^{[31]}$.
Analysis on pupillary constriction, electroencephalogram (EEG), and subjective evaluation on flickering perception were done.

Expected results were placed in a more specific understanding of the non-visual effects of flickering light in different frequencies but at the same duty ratio in order to define the most suitable frequency to adapt to a task lamp designed for this type of jobs by delivering a greater state of alertness for the user and not disturbing the ambiance lighting conditions in their perception.

\section{METHODS}

Subjects: 11 young males (age: $24 \pm 4$ years) with normal vision participated in the experiment. Each subject was exposed to different continuous stream of pulses of monochromatic BP and BGP LED light conditions; pulses at 100, 200, and $400 \mathrm{~Hz}$ over two background light colors (BLC) $(2700 \mathrm{~K}$ at $30 \mathrm{~lx}$ and $6500 \mathrm{~K}$ at $30 \mathrm{~lx}$ ) for a total of 12 conditions.

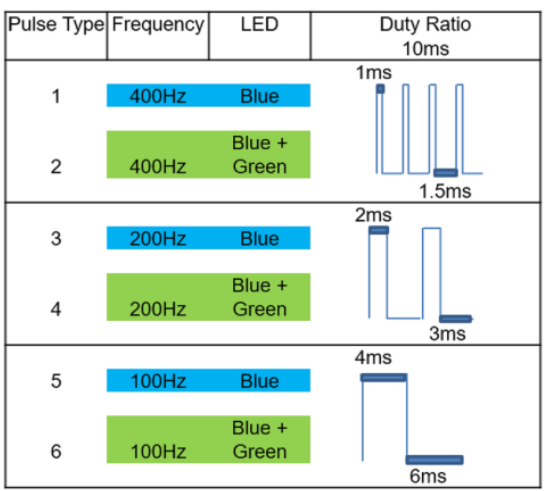

FIGURE 1. Flickering frequency and duty ratio.

Duty ratios were the same for the different frequencies (Figure 1), and the irradiance was set to $200 \mu \mathrm{W} /$ $\mathrm{cm}^{2}$ for each of the LED colors and the Blue LED, and Green LED spectral power distribution (SPD) are shown in Table 1 and Figure $2^{[41]}$.

The number of participants requested was small as per the type of experimental procedure performed which was as a continuous variable type to be measured. 
TABLE 1. Irradiance settings

\begin{tabular}{|c|c|c|c|c|}
\hline $\begin{array}{c}\text { Light } \\
\text { Condition }\end{array}$ & $\begin{array}{c}\text { Irradiance } \\
\left(\mu / \mathrm{Wcm}^{2}\right)\end{array}$ & $\begin{array}{c}\text { Photon } \\
\text { Density } \\
\left(\mathrm{photons} / \mathrm{cm}^{2} / \mathrm{S}\right)\end{array}$ & $\begin{array}{c}\text { Photopic } \\
\text { Illumination } \\
(1 \mathrm{x})\end{array}$ & $\begin{array}{c}\text { Scotopic } \\
\text { Illumination } \\
(1 \mathrm{x})\end{array}$ \\
\hline Blue & 200.00 & $4.8 \times 10.14$ & 150 & 2235 \\
\hline Green & 200.00 & $5.4 \times 10.14$ & 1130 & 2514 \\
Blue + Green & 400.00 & $1.0 \times 10.14$ & 1265 & 4800 \\
\hline
\end{tabular}

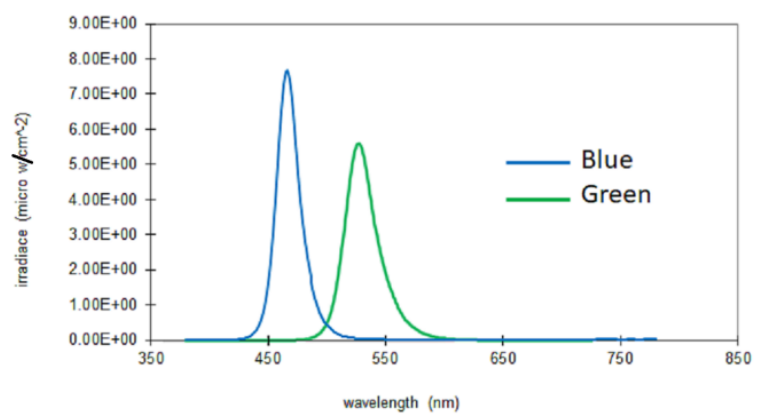

FIGURE 2. Blue and Green LED Spectral Power Distribution.

When the sample definition took place, a single group of individuals has to be evaluated by a crossover type of experiment as a repeated measurements type. It is needed then to measure the effect on each individual on every treatment, as there is no control group, each person is considered his own control, and with this we can eliminate the effect of subject variation in data and eliminate the possible interindividual variability.

Age group was also selected in a close range to avoid significant differences in EEG readings as some studies demonstrate that age reduces the effect of light on brain functions [33] [34] [35].

The experiment was conducted between 10:00 a.m. and 12:00 pm. In the space where measures were taken, a chair and an integrating sphere were placed along with a head and chin rest device to avoid any movement of the face while recording the pupil behaviour.

Temperature was controlled by an air conditioner unit; maintained at $21^{\circ} \mathrm{C}$ with an SD of $\pm 1.6^{\circ} \mathrm{C}$ and no windows were in the room. One access door was kept closed to avoid any noise or outside light contribution; there was no activity involved in the participant's intervention other than keep looking into the inside of the integrating sphere, hence no additional experimental noise was influencing the test (Figure 3).

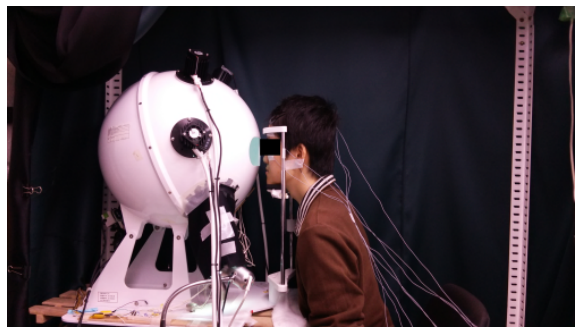

FIGURE 3. Participant and Integrating Sphere.

The process to obtain the EEG data was performed through the use of a MP150 System, BIOPAC Systems Inc. ${ }^{\circledR}$. Placement of electrodes (BIOPAC Systems Inc. ${ }^{\circledR}$, EL254S; Silver-silver chloride,-Ag-AgCl) were located at the frontal lobe $(\mathrm{Fz})$, occipital $(\mathrm{Oz})$ and the central (Cz) scalp locations according to the International 10-20 system. Thus, as a non-invasive procedure; in a way that the placement of the electrodes was done by measuring the scalp and identifying the locations of placement, then, by adding conductive paste (Elefix, Z-181JE) and fixing them manually. A fourth electrode has to be placed on the earlobe as a point of reference ('ground') of the body's baseline voltage due to other electrical activities (noise). Due to natural eye movements during the test, Electro-oculogram (EOG) measurements are generated, so four electrodes were also placed; this EOG's electrodes are located one above and one below each eye over the Orbicularis oculi muscle. All electrodes impedance was kept at $<5 \mathrm{~K} \Omega$, and revised with impedance measurement device MaP811 (Nihon sound tech MAP No. 116-032).

Selection of Occipital and Central locations in the scalp were taken as the presence of light and the primary visual cortex is most related to the Occipital lobe rather than the frontal lobe where Cognitive work in brain is normally measured ${ }^{[33]}$ although, frontal lobe 
was also measured for countercheck. EEG data was acquired at $1 \mathrm{KHz}, 1$ second epochs were taken but full raw data was considered as the base measure; EOG's artefacts were removed by bypass filtering the channels (BIOPAC Systems Inc. ${ }^{\circledR}$, Acknowledge software V4.1). Then, data was processed by Fast Fourier Transform function (FFT) and data is band pass filtered at 4-8 $\mathrm{Hz}$ for Theta waves, 8-13 $\mathrm{Hz}$ for Alpha, 13-30 Hz for Beta and 31-45 Hz for Gamma waves; were the ranges used for posterior analysis in frequencies of brain responses.

The BP-LED flickering rate was generated using a pulse width modulation signal delivered by a programmable board (mbed ${ }^{\circledR}$, NXP LPC1768, LPCXpresso BOARD, ARM Corp. LTD.), and then verified using an oscilloscope (TEKTRONIX ${ }^{\circledR}$, TPS 2024B). The pulse rate was maintained at $100 \mathrm{~Hz}$ in which $1 \mathrm{~ms}$ for 'on' state and $1.5 \mathrm{~ms}$ for 'off' state. At $200 \mathrm{~Hz}$ the rate was $2 \mathrm{~ms}$ for 'on' state and $3 \mathrm{~ms}$ for 'off' state; and at $400 \mathrm{~Hz}$ the rate which was $4 \mathrm{~ms}$ for 'on' state and $6 \mathrm{~ms}$ for 'off' state (Figure 1). The type of LED used in the flickering lamps were of the type high power blue LED and green LED (16 W 24-AB2S, KASHINOKI SOGYO CO., LTD.).

The irradiance was set at $200 \mu \mathrm{W} / \mathrm{cm}^{2}$ for the different LED lights and checked by using the CL500A, Konica ${ }^{\circledR}$ Minolta Optics Inc. meter (Figure 2 and Table 1). The peak wavelength and the full width at half maximum (FWHM) for the short- and long-wavelength lights were $470 \mathrm{~nm}$ with an FWHM of $25 \mathrm{~nm}$; and $630 \mathrm{~nm}$ with an FWHM of $25 \mathrm{~nm}$, respectively.

Pupil size was recorded by using pupil diameter (PD) taken by a camera and equipment (EMR-8B, NAC Image Technology Inc.) placed in front of the participant and inside the integrating sphere and then calculated the \% pupil constriction in two different periods of the exposures. As per previous research from Takahashi et al. ${ }^{[13]}$ in which estimated that the irradiance level at which the role of rods in pupillary constriction were replaced by ipRGCs was around $4.54 \mu \mathrm{W} / \mathrm{cm}^{2}$ ipRGCs, it was proposed in Katsuura et al. ${ }^{[31]}$ that the blue pulsed light of strong irradiance induced significantly greater pupillary response. Therefore we compared this statement to what we obtained as a result; with the difference that, the present experiment delivered a continuous stream of pulses rather than a single pulse with time in between pulses for the pupil to recover as in those previous studies.

The constriction ratio (CR) was calculated by two formulas, considering 2 different periods of exposure. For the T1 period (CRT1), all data were analyzed considering the same sample size for each of the conditions; and, the average pupil diameter (PD) of $1 \mathrm{sec}$ Prior Pulse Insertion ("PPI"), and, the minimum PD value in the Ffirst 5 Seconds ("F5s") after pulse insertion for the first analysis (Formula 1) and for the T2 period of time (CRT2); considered the average of $1 \mathrm{sec}$ prior pulse insertion ("PPI") and the average value in the second segment of 5 seconds ("S5s") after pulse insertion for the first analysis (Formula 2).

\section{Formula 1}

[(average PD of 1 sec prior insertion - minimum PD size in the first 5 seconds after light insertion)] average PD of 1 sec prior insertion

$$
\mathrm{CRT} 1=[(\text { (“PPI”) }-(\text { (“F5s”) }] \text { ( (“PPI”) }
$$

\section{Formula 2}

[(average PD of 1 sec prior insertion - average PD size in the 2nd period of 5 seconds after light insertion)] average PD of 1 sec prior insertion

$$
\mathrm{CRT} 2=[(\text { (“PPI”) }-(\text { (“S5s”) }] \text { ( (“PPI”) }
$$

Equipment used at the laboratory is not for clinical diagnostics, devices are designed to record data for only a non-invasive experimental type of procedures. 


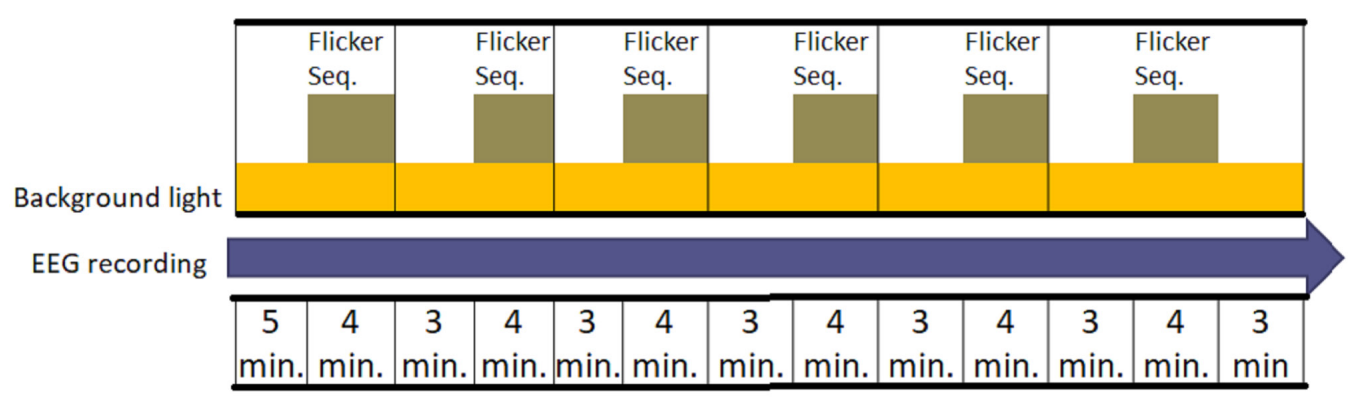

FIGURE 4. Experimental Diagram.

\section{PROCEDURE}

Sequence and procedure obey to a true experimental type of design. It is considered a longitudinal analysis, as all participants received every treatment in a counterbalanced procedure (Multiple crossover); therefore, there was no control group; thus, repeated measures were taken as a single blinded type of experiment ${ }^{[36]}$ [37].

By applying the Balanced Latin Square Design [38] [39] for counterbalanced procedures, the treatments were sorted to avoid any carry over effect or fatigue during the exposures. To avoid participants knowing the type of treatment they were going to receive, the previously counterbalanced sequence was randomly assigned to each subject. Participants were instructed to avoid consumption of alcoholic or caffeinated beverages so as to have a good sleep the previous night; they were also asked if they have had worked in shifts or travelled across time zones in the previous month. As part of the experimental procedure the participants were informed about it and they signed the inform consent according to the Ethics Committee of Chiba University, in Japan, where it took place.

The participants arrived to the experiment on the selected day; the time when it was conducted was between 10:00 am to 12:00 p.m. this was to coincide with what is recognized as the lowest melatonin secretion time during the day ${ }^{[40]}$. During the first $30 \pm 5 \mathrm{~min}$, the electrodes of the EEG and the pupil size camera detector measuring device were placed and adjusted. Simultaneously, the participants faced the integrating sphere (Figure 4), which had already been set for the background light condition to be measured; this was the adaptation period.

Only one participant per day was exposed to the whole sequence with one background light condition of that day, then in a different day but at the same time, the other background light condition was processed.

Each subject sat on a chair with his eyes facing the integrating sphere (Figure 3) in a straight position, and resting their chin and head in a support during all tests. The LEDs and a desk type LED lamp were previously installed inside the integrating sphere. After 10 minutes of background light adaptation, the subject was exposed to a stream of pulses of LED light for 4 minutes, then back to the background light for 3 minutes and exposed again to the next stream of pulses; this was repeated for the 6 different types of pulses in one session. Pulses were sorted in a counterbalanced manner, as mentioned before, so as the background light used on that day's session.

The subjects performed the experiment as shown in Table 2 and Figure 4. During the process, measures of pupil size were taken full time but requested to maintain his eyes open for 5 seconds prior to the first LED stream appearance and to sustain the eyes open for 10 
TABLE 2. Experimental procedure

\begin{tabular}{|c|c|c|c|}
\hline Step & $\begin{array}{l}\text { Start time } \\
\text { (Approximate) }\end{array}$ & $\begin{array}{l}\text { Task } \\
\text { (All activities are done between the examiner and the participant) }\end{array}$ & $\begin{array}{c}\text { Duration } \\
\text { (Minutes) }\end{array}$ \\
\hline 1 & 10:00 a. m. & $\begin{array}{l}\text { Arrival of participant, first light condition is already set in the integrating sphere. } \\
\text { Electrodes for EGG, are attached by the examiner. } \\
\text { At the same time instructions are given to the subject about the procedures for the pupil measurement. } \\
\text { This is the adaptation period for the participant. }\end{array}$ & 35 \\
\hline 2 & $10: 35$ a. m. & Pupil Size Calibration, participant's pupil is targeted and data is stored, under background light only. & 5 \\
\hline 3 & $10: 40$ a. $\mathrm{m}$. & $\begin{array}{l}\text { Exposure to Background light in the sphere continues. } \\
10 \text { seconds before inserting flickering pulse, and } 10 \text { seconds after; participant is requested to keep his/her } \\
\text { eyes open without blinking. }\end{array}$ & 5 \\
\hline \multirow[b]{2}{*}{4} & 10:45 a. m. & Insertion of first flickering type is applied. & \multirow[b]{2}{*}{4} \\
\hline & 10:49 a. m. & $\begin{array}{l}10 \text { seconds before exposure ends, and } 10 \text { seconds after; participant is also requested to keep his/her eyes } \\
\text { open to record pupil size when flickering is off. }\end{array}$ & \\
\hline \multirow[t]{6}{*}{5} & $10: 49$ a. m. & $\begin{array}{l}\text { First flickering type is turned off. } \\
\text { Exposure to Background light in the sphere remains, participant is asked about flickering perception. }\end{array}$ & \multirow[t]{2}{*}{3} \\
\hline & & $\begin{array}{l}\text { STEPS } 4 \text { AND } 5 \text { ARE REPEATED FOR THE } 6 \text { DIFFERENT STREAM OF PULSES } \\
\text { WHEN THE }{ }^{\text {TH }} \text { STREAM OF PULSES IS TURNED OFF, THEN: }\end{array}$ & \\
\hline & $11: 27$ a. m. & Participant is requested to rest for 3 minutes. & 3 \\
\hline & $11: 27$ a. m. & End of experiment. & \multirow{2}{*}{10} \\
\hline & $11: 37$ a. m. & Removal of devices is taken place. & \\
\hline & $11: 45$ a. m. & $\begin{array}{l}\text { End of Session. } \\
\text { Total of Session (+/- } 5 \text { minutes). }\end{array}$ & 97 \\
\hline
\end{tabular}

seconds once activated; then they had to keep looking into the sphere but blinking normally To review changes before and after the exposure to the light condition; eyes were requested to be fully open during 5 seconds while they were looking through the integrating sphere at a target previously marked on the inside of the sphere. Flickering perception was evaluated by a single qualitative question during each take after each flickering ended.

For the statistical analysis, a parametric test was chosen as normality was assumed and the data on our dependent variables was measured on a continuous scale. The sample $\mathrm{N}=\mathbf{1 1}$, data was expected to have statistical significance of $\mathrm{p}<0.05$, and a $\mathrm{p}<0.1$ for a consideration as a tendency.

The data were collected from various sources and processed in the IBM SPSS ${ }^{\circledR}$, v20 software by repeatedly conducting the analysis of variance (ANOVA) in a $2 \times 2 \times 3$ matrix that compared the 2 background light color temperatures (BLC), BP-LED and BGP-LED intervention, and the 3 different frequencies of flickering used; after which Bonferroni`s post hoc test was evaluated for significance. These were applied to the entire physiological data, both, pupil size and EEG data.

Independent variables in the ANOVA analysis were the 2 BLC, the 3 different frequencies, BP-LED and the BGP-LED. Dependent or non-controlled variables were those such as the intrinsically noise in a measurement like those related to the physiological measurements of the participant; pupil size, and EEG response to light.

\section{RESULTS AND DISCUSSION}

\section{Pupillary constriction}

From the measurement of the pupil diameter (PD) (EMR-8B, NAC Image Technology Inc.), we obtained the pupil behaviour in all the exposures (Figure 5). And then calculated the percentage of pupil constric- 


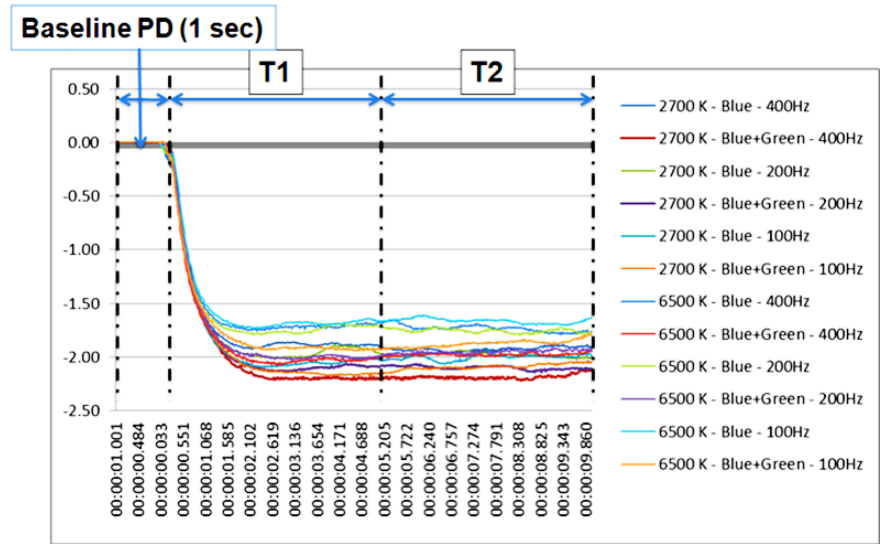

FIGURE 5. Pupil behaviour during exposures.

Pupil constriction in percentage [(baseline PD - minimum PD in the initial 5 sec after light exposure) / baseline PD] x 100

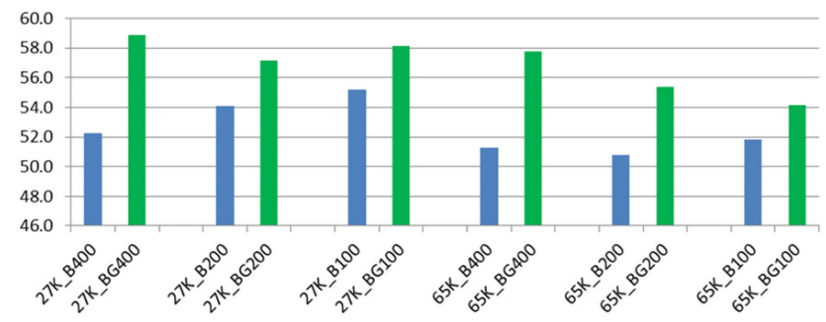

FIGURE 6A. Pupil constriction in percentage, T1 period.

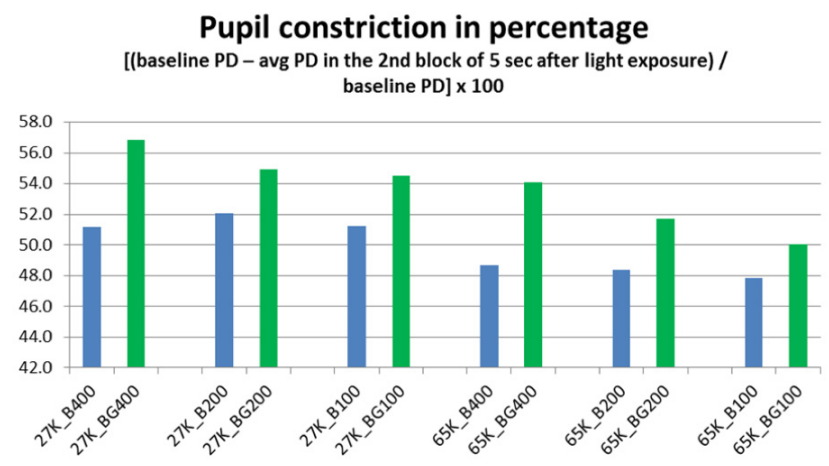

FIGURE 6B. Pupil constriction in percentage, T2 period.

tion (CR) in two different periods of the exposures (T1 and T2) (Fig. 6 a, b). The periods were placed from the moment of the light insertion and up to the first $5 \mathrm{sec}-$ onds (T1) and from the 5th second's line up to the 10th seconds line (T2); these periods were selected to study the pupil behaviour in regards to constriction proportion (T1) and pupil size stabilization (T2).
The pupillary constriction in response to simultaneous pulsed BGP LED light was significantly larger $(p<0.01)$ (Figure 7$)$ than that during BP LED light exposure. The BLC also reflected a significant difference $(\mathrm{p}<0.05)$ when low color temperature light was used (Figure 8).

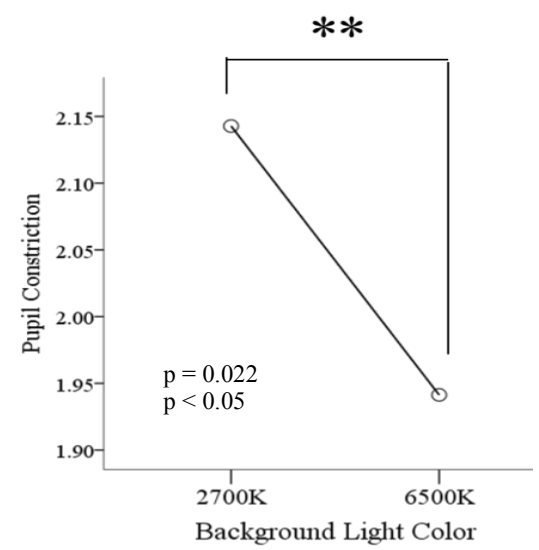

FIGURE 7. Pupil constriction under background colors, T1 period.

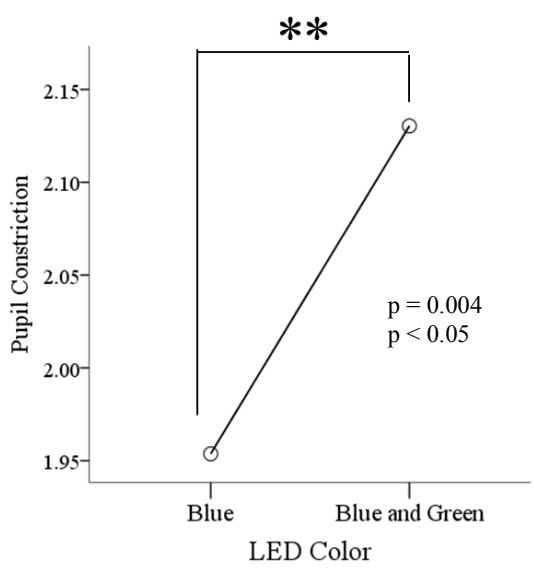

FIGURE 8. Pupil constriction under BPLED and BGPLED insertion, T1 period.

In the second analysis (T2) also denoted statistical significant constriction result $(\mathrm{p}<0.05)$ in response to simultaneous pulsed BGP LED which was significantly larger (Figure 9) than that during BP LED light exposure. The BLC also reflected a significant difference $(\mathrm{p}<0.01)$ when low color temperature light was used as in the $\mathrm{T} 1$ period resulted (Figure 10). 


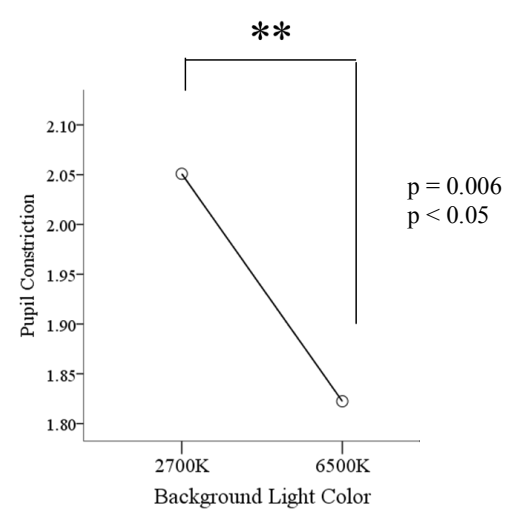

FIGURE 9. Pupil constriction under background colors, T1 period.

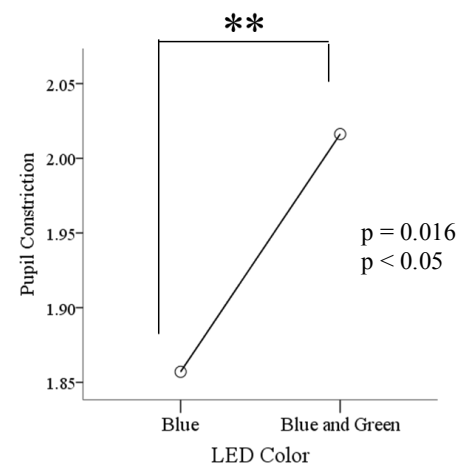

FIGURE 10. Pupil constriction under

BP LED and BGP LED insertion, T2 period.

\section{EEG results}

In regards to the EEG results, overall measurements were considered for the following relations to brain waves theta, alpha and beta by applying the Formulas 3, 4 and 5:

Formula 3. $\Theta=\Theta /(\Theta+\alpha+\beta)$

Formula 4. $\alpha=\alpha /(\Theta+\alpha+\beta)$

Formula 5. $\beta=\beta /(\Theta+\alpha+\beta)$

For specific relation among waves it was also compared to verify the state of alertness as Formulas 6, 7, 8 and 9.

Formula 6. $\alpha=\alpha / \Theta$
Formula 7. $\Theta=\Theta / \alpha$

Formula 8. $\alpha=\alpha / \beta$

Formula 9. $\beta=\beta / \alpha$

All of the previous measures were reviewed for the $\mathrm{Fz}, \mathrm{Cz}$ and $\mathrm{Oz}$ locations of the scalp and repeated measures among dependent and independent variables were calculated and resulted as described in the following paragraphs (only significant results are shown).

For the Alpha and Theta relation, data denoted a significant result in BLC and LED color comparisons, results were $\mathrm{p}=0.019$ (Figure 11 ).

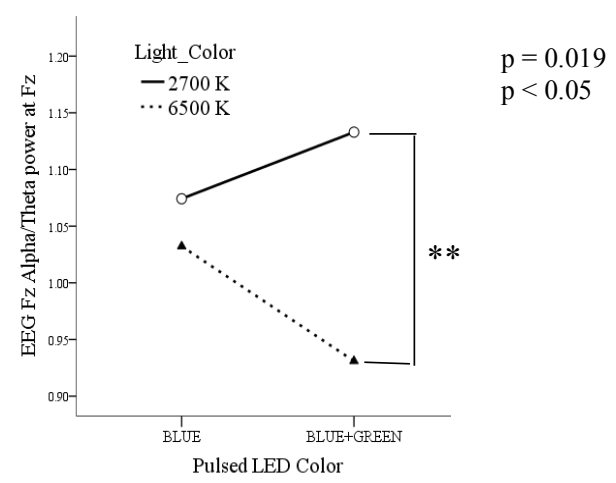

FIGURE 11. EEG Alpha/Theta at Fz location,

Pulsed LED insertion.

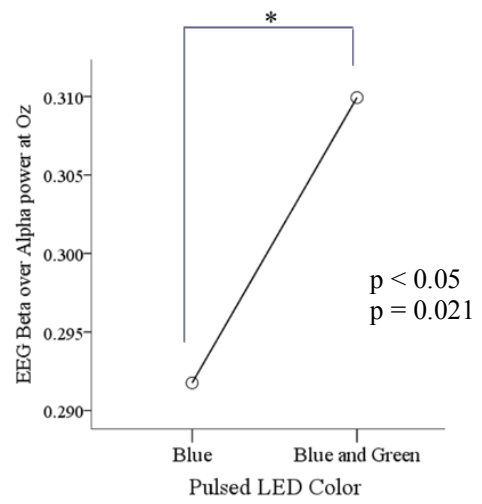

FIGURE 12. EEG Beta/Alpha at Oz location, Pulsed LED.

In regards to flickering frequencies, although there were some interesting behaviours of the EEG waves, none of them showed a statistically significant result among them. 
As during the test and after each stream of light exposure, participants were requested to give a qualitative evaluation about their own perception of flickering as a subjective evaluation, resulting that flickering perception was not perceived by participants in $100 \%$ of the exposures with both BP LED and BGP LED streams.

Constriction rate in BGP LED is larger than BP LED. Background light seems to affect directly to the constriction rate. It might suggest that the combination of Pulsed LED and Background lights has a direct effect on pupil size. This could imply that the ratio of pupil to constrict is longer in backgrounds with high color temperature conditions as those with low color temperature conditions.

Pupil size denoted as per the results in pupillary constriction, that the statement proposed in Katsuura et al. ${ }^{[31]}$ in which blue pulsed light of strong irradiance induced significantly greater pupillary response; in our case was reviewed under a continuous stream of pulses rather than a single pulse with time in between pulses for the pupil to recover as in that previous study; denoting that the combination of BGP LED delivers a greater constriction compared to the $\mathrm{BP}$ LED, which adds in knowledge to what was studied before by Takahashi et al. ${ }^{[13]}$ in which estimation of the irradiance level at which the role of rods in pupillary constriction were replaced by ipRGCs was around $4.54 \mu \mathrm{W} / \mathrm{cm}^{2}$ ipRGCs is also confirmed.

Figueiro et al. $2008{ }^{[2]}$ stated that "Brightness perception is inherently sub additive in its response to light due to input from the spectral opponent channels. For example, adding a "green" light to a "red" light will decrease the response of the r-g system, desaturating the vividness of the red light and reducing the apparent brightness of the red light even though more light has been added to it."; It is possible that by using only Blue or combining Blue and Green the spectral opponent channels are not triggered, therefore the sub additive response analyzed in Katsuura et al ${ }^{[31]}$ is not evident although irradiance in the present experiment is well over the estimation ipRGCs triggering level estimated by Takahashi et al ${ }^{[13]}$.

In regards to the EEG readings during the test, for the $\alpha / \Theta$ relation, data denoted a significant result in BLC and also Pulsed LED color insertion comparisons, although results were statistically significant for $\alpha / \Theta$ in all scalp locations denoting that participants were awake during the test, perhaps it is to consider that $2700 \mathrm{~K}$ has a higher influence in evoking awakeness than $6500 \mathrm{~K}$.

Compelling result came out the $\beta / \alpha$ measurement analysis as results suggest significant changes in responses during the interaction of background light color, LED, and EEG. Beta waves exhibited a statistical significance $(p<0.05)$ in arousal levels when exposed to BGP LED light, although no active task was involved during exposure. Furthermore, the pupil reacted with larger constriction towards BGP LED exposure than towards monochromatic BP LED exposure, perhaps due to the double irradiance intensity of the combination; thus demonstrating that a continuous stream of pulses can deliver the irradiance. Perception of change on the ambiance light was not affected due to flickering as per qualitative evaluation results of the participants on flickering perception; it was a $100 \%$ evaluated as "no flickering perception". This is a very important health factor to review which reflected not to affect perception among the frequencies applied. Also, the difference in EEG readings gave to the study the validity of which one could be more effective in delivering alertness among the frequencies used, in our case $100 \mathrm{~Hz}$ work elicited the most.

\section{CONCLUSIONS}

Our findings demonstrated the effect on response to pulsed light on pupillary constriction and EEG responses. As per previous research [26] [27] [28] [29] [30] and results obtained; if we know that ipRGCs activation is 
related to brain activation (alertness) and cognitive performance, then by reviewing our pupil constriction results, which means ipRGCs have been activated; then, alertness should have been evoked (Fig 11 and 12). It can be concluded that the use of flickering light and that color of light can evoke the most of alertness in our current experimental arrangement even though no active task was performed.

This study supports the previous finding that BP LED helps to improve the state of alertness ${ }^{[10]}$ and therefore it can be applied in what was proposed by adding the continuous pulsed LED light to a task lamp in order to be used in a daily work situation such as that in offices, hospitals, or schools, just with the consideration of adding the green LED to the previously proposed task lamp; as results in the current study, demonstrated that the addition of blue and green LED light evokes alertness and then the idea of making a double color LED lamp can be an available option for the customer.

The use of a flickering emitted beam of light as part of our original experimental design, resulted in a positive effect as depending on the intensity of the irradiance we can reduce it and eliminated the bluish or bluish/green color sensation on our work surface, as it was demonstrated in this experiment that by flickering the light, the perception of a continuous streams of light remains and there is no sensation of being illuminated by a flickering light at all.

This study supports possible applications of continuous pulsed light as a mean to improve alertness in our daily activities although in the present study, the tests were done in a laboratory set up, the materials and parameters used are the same to those that can be applied in the end product that may result from this research.
Circadian Rhythm studies reveal that the best time of the day for blue enriched light exposure is during the morning hours, if blue spectrum is delivered at different time of the day it may affect the phase of the circadian cycle, therefore evoking alertness by suppressing melatonin; so, if supplied during night shifts of work, exposure has to be controlled so in a way that persons are not affected substantially to their circadian rhythm.

In regards to the subadditivity response, could be a good reference as a future step to measure pulsed Blue + Green LED with the same background and frequency conditions only adjusting the irradiance to $\mathrm{a} 1 / 2$ $+1 / 2$ factor to deliver a total of $200 \mu \mathrm{W} / \mathrm{s} / \mathrm{cm}^{2}$ (100 each color) and verify if subadditivity is tied to equal irradiances and triggers the spectral opponent channels.

\section{ACKNOWLEDGEMENTS}

This project was possible with the support of KAKENHI Grant Number 15K14617 and 26291098, Japan and Chiba University, Faculty of Engineering, Department of Design in the Humanomics Section; the National Council of Science and Technology of México (CONACYT-I2T2) (GrantNo. 115018/314341-CVU84989); and the University of Monterrey (UDEM) in México for the support with their FAE (External Academic Formation) program.

\section{COMPETING INTERESTS}

The authors declare that they have no competing interests.

\section{ETHICS APPROVAL AND CONSENT TO PARTICIPATE}

Chiba University Ethics Committee, 2016 approved.

\section{CONSENT FOR PUBLICATION}

Signed by authors as requested by the RMIB. 


\section{REFERENCES}

[1] Iwata T, Noguchi H. (2015). Nighttime lighting based on circadian rhythm (indoor lighting at night taking effect of light on circadian rhythm into consideration). J Illum Engng Inst Jpn.; 99(1):35-6.

[2] Higuchi S. (2013). Non-visual effects of light and circadian rhythm: approach to physiological polytypism. Jpn J Physiol Anthropol; 18(1):39-43.

[3] Higuchi S. (2011). Non-visual effects of light: adaptation to light environment (<special issue> Lighting Research Group). Jpn J Physiol Anthropol.; 16(1):21-6.

[4] Huang J, Shimomura Y, Katsuura T. (2012). Effects of monochromatic light on different time perception. J Human Environ Sys.; 15(1):21-9.

[5] Noguchi H, Sakaguchi T. (1999). Effect of illuminance and color temperature on lowering of physiological activity. Appl Human Sci.;18:117-23. doi:10.2114/jpa.18.117.

[6] Yasukouchi A, Ishibashi K. (2005). Non-visual effects of the color temperature of fluorescent lamps on physiological aspects in humans. J Physiol Anthropology, Appl Hum Sci.; 24:41-3. doi:10.2114/ipa.24.41.

[7] Katsuura T, Jin X, Baba Y, Shimomura Y, Iwanaga K. (2005). Effects of color temperature of illumination on physiological functions. J Physiol Anthropology, Appl Hum Sci.; 24:321-5. doi:10.2114/jpa.24.321.

[8] Jin X, Katsuura T, Iwanaga K, Shimomura Y, Inoie M. (2007) The influence of taste stimuli and illumination on electrogastrogram measurements. J Physiol Anthropol.; 26:191-5.

doi:10.2114/jpa2.26.191.

[9] Ishibashi K, Kitamura S, Kozaki T, Yasukouchi A. (2007). Inhibition of heart rate variability during sleep in humans by $6700 \mathrm{~K}$ pre-sleep light exposure. J Physiol Anthropol.; 26:39-43. doi:10.2114/ipa2.26.39.

[10] Chaveznava C, Shimomura Y, Katsuura T. (2018). Physiological Effects of Blue Pulsed LED in an Indoor Lighting Environment. Revista Mexicana de Ingeniería Biomédica: 39(3):271-290. dx.doi.org/10.17488/RMIB.39.3.6

[11] Münch M, Bromundt V. (2012) Light and chronobiology: implications for health and disease. Dialogues Clin Neurosci.; 14(4):448-53.

[12] Berson D, Dunn F, Takao M. (2002). Phototransduction by retinal ganglion cells that set the circadian clock. Science; 295(5557):10703. doi:10.1126/science.1067262.

[13] Takahashi Y, Katsuura T, Iwanaga K, Shimomura Y. (2010). Contribution of intrinsically photosensitive retinal ganglion cells on action spectrum for pupillary light reflex. J Illum Engng Inst Jpn.; 94:743-6. doi:10.2150/jieij.94.743.

[14] Lee H, Katsuura T, Iwanaga K, Shimomura Y, Higashi H, Ichijo T. (2008). The effect of monochromatic light exposure on human physiological responses. Jpn J Physiol Anthropol.; 13(2):75-83.

[15] Takahashi Y. (2011) Photoreceptor caused by non-image-forming effect (<special issue > Lighting Research Group). Jpn J Physiol Anthropol.; 16(1):27-30.
[16] Figueiro M, Bierman A, Plitnick B, Rea M. (2009). Preliminary evidence that both blue and red light can induce alertness at night. BMC Neurosci.; 10:105.doi:10.1186/1471-2202-10-105.

[17] Lockley S, Evans E, Scheer F, Brainard G, Czersler C, Aeschbach D. (2006). Shortwavelength sensitivity for the direct effects of light on alertness, vigilance and the waking electroencephalogram in humans. Sleep; 29(2):161-8.

[18] Vandewalle G, Collignon O, Hull JT, et al. (2013). Blue light stimulates cognitive brain activity in visually blind individuals. J Cogn Neurosci.; 25:2072-85.

[19] Lockley SW. (2003). High sensitivity of the human circadian melatonin rhythm to resetting by short wavelength light. J Clin Endocr Metab.; 88(9):4502-5.

[20] Warman VL. (2003). Phase advancing human circadian rhythms with short wavelength light. Neurosci Lett.; 342(1-2):37-40.

[21] Lall GS, Revell VL, Momiji H, et al. (2010). Distinct contributions of rod, cone, and melanopsin photoreceptors to encoding irradiance. Neuron; 66:417-28.

[22] Gooley JJ, Ho Mien I, St Hilaire MA, et al. (2012). Melanopsin and rod-cone photoreceptors play different roles in mediating pupillary light responses during exposure to continuous light in humans. J Neurosci.; 32:14242-53.

[23] Ho Mien I, Chua EC, Lau P, et al. (2014). Effects of exposure to intermittent versus continuous red light on human circadian rhythms, melatonin suppression, and pupillary constriction. PLoS One.; 9:e96532.

[24] Katsuura T, Ochiai Y, Senoo T, Lee S, Takahashi Y, Shimomura Y. (2012). Effects of blue pulsed light on human physiological functions and subjective evaluation. J Physiol Anthropol.; 31:23. doi:10.1186/1880-6805-31-23.

[25] Berson DM, Dunn FA, Takao M. (2002). Phototransduction by retinal ganglion cells that set the circadian clock. Science.; 295(5557):1070-3.

[26] Takahashi Y, Katsuura T, Shimomural Y, Iwanaga K. Prediction model of light-induced melatonin suppression. J Illum Engng Inst Jpn. 2010;94:2.

[27] Stockman A, Sharpe LT, Fach C. (1999). The spectral sensitivity of the human shortwavelength sensitive cones derived from thresholds and color matches. Vision Res.; 39:2901-27.

[28] Lamb T. (1995). Photoreceptor spectral sensitivities: common shape in the longwavelength region. Vision Res.; 35:3083-91.

[29] Yuka S, Hideo A, Makoto N, Kaori N, Yoshie Y, Michiko H, Yoshiyasu T, Junko M, Mihoko M, Kunio H, Tatsuya I. (2007). Effects of short-term exposure to wholebody vibration on wakefulness level. Ind Health.; 45:217-23.

[30] Xinxin L, Koichi I, Shigeki K. (2011). Circulatory and central nervous system responses to different types of mental stress. Ind Health.; 49:265-73.

[31] Katsuura et al. (2012). Effects of blue pulsed light on human physiological functions and subjective evaluation. Journal of Physiological Anthropology; 31:23-26. 
[32] Cajochen C, et al. (2005). High sensitivity of human melatonin, alertness, thermoregulation, and heart rate to short wavelength light. Journal of Clinical Endocrinology Metabolism; 90: 1311-1316.

[33] Daneault, V., Hébert, M., Albouy, G., Doyon, J., Dumont, M., Carrier, J., \& Vandewalle, G. (2014). Aging reduces the stimulating effect of blue light on cognitive brain functions. Sleep, 37(1), 85-96. http://doi.org/10.5665/sleep.3314

[34] Vandewalle, G., Balteau, E., Phillips, C., Degueldre, C., Moreau, V., Sterpenich, V., Maquet, P. (2006). Daytime Light Exposure Dynamically Enhances Brain Responses. Current Biology, 16(16), 1616-1621. http://doi.org/10.1016/j.cub.2006.06.031

[35] Cabeza, R., Daselaar, S. M., Dolcos, F., Prince, S. E., Budde, M., \& Nyberg, L. (2004). Task-independent and Task-specific Age Effects on Brain Activity during Working Memory, Visual Attention and Episodic Retrieval. Cerebral Cortex, 14(4), 364-375. http://doi.org/10.1093/cercor/bhg133

[36] Cohen, J. (1988). Statistical Power Analysis for the Behavioral, Sciences. 2nd ed. Hillsdale, NJ: Lawrence Erlbaum; 567 p.

[37] Hopkins, W. G. (2008). Research designs: Choosing and fine-tuning a design for your study. Sportscience. 12:12-21. Retrieved from: http://search.ebscohost.com/login.aspx?direct $=$ true $\& d b=s 3 h \& A N=36$ 005990\&lang $=$ cs\&site $=$ ehost-live
[38] Girden, E.R., (1992). ANOVA: Repeated Measures, Newbury Park, CA: Sage University Press Series on Quantitative Applications in the Social Sciences, 07-084, ISBN: 9780803942578

[38] Iverson, G. R. and Norpoth, H., (1986), Analysis of Variance, 2nd ed. Newbury Park, CA: Sage University Press Series on Quantitative Applications in the Social Sciences, 07-001

[40] Higuchi, S., Ishibashi, K., Aritake, S., Enomoto, M., Hida, A., Tamura, M., Mishima, K. (2008). Inter-individual difference in pupil size correlates to suppression of melatonin by exposure to light. Neuroscience Letters, 440(1), 23-26. http://doi.org/10.1016/j.neulet.2008.05.037

[41] Katsuura, T., Soomin, L. (2019) A review of the studies on nonvisual lighting effects in the field of physiological anthropology. Journal of Physiological Anthropology 38:2. https://doi.org/10.1186/s40101-018-0190-x 